\title{
Post-concussive syndrome in a female basketball player: a case study
}

This article was published in the following Dove Press journal:

Open Access Journal of Sports Medicine

13 May 2013

Number of times this article has been viewed

\section{Sarah L Strand \\ Department of Health and Human Sciences, Loyola Marymount University, Los Angeles, CA, USA}

\begin{abstract}
The objective of this case study was to identify the signs and symptoms of concussion and post-concussive syndrome in a collegiate, female basketball player, as well as her progress to becoming symptom free. The patient, a previously healthy, 21-year-old with no previous head injuries, experienced a concussion and continued to participate in her sport. Even though the athlete knew the risks of playing while symptomatic, she did not report her symptoms, and continued playing until the season ended. This case highlights that even when patients know the risks, they may be willing to overlook them to continue playing and it emphasizes the importance of further education. In addition, it shows that even when following recommended guidelines, and with normal neurocognitive testing, symptoms may come back upon return to play.
\end{abstract}

Keywords: concussion, basketball, mild traumatic brain injury, female athletes

\section{Case study}

In 2008 a 21-year-old female, National Collegiate Athletic Association (NCAA) university basketball point guard sustained a concussion in the second game of her junior season. The athlete was pinned between two players and was subsequently struck on the left side of the frontal bone. She was fouled on the play, and recalled feeling dizzy and lightheaded at the time, but was composed enough to make both free throws, and complete the rest of the game. Immediately following the game, her chief complaints were headache, nausea, loss of appetite, and fatigue. Following the game, at the team dinner, her teammates noticed that she was uncharacteristically quiet. She also felt tired, experienced a lack of appetite and the onset of a headache. As the night progressed the athlete began to feel nauseated and had an increase in what she described as a "hazy" feeling. Also, when she returned to the hotel room where the team was staying, she felt confusion and began crying for no particular reason for which she was aware. Before retiring to bed she took ibuprofen.

There was no certified athletic trainer (ATC) traveling with the basketball team for this road trip and the athlete did not report her symptomatology to either the coaching staff or to the ATC at the tournament. She did however report to a teammate, when her behavior was questioned, that she thought it was possible she had a concussion. It is of note that the athlete was an athletic training student in her University's athletic training education program (ATEP) and had knowledge of concussion signs/symptoms.

The day after the blow to the head, the athlete participated in another game at the tournament. She performed at an uncharacteristically low level during this game as,
Correspondence: Sarah L Strand

Department of Health and Human Sciences, Loyola Marymount

University, I LMU Drive,

Los Angeles, CA, USA

Tel + I 3105686646

Email sstrandI@Imu.edu 
typically, she was an aggressive player and did not perform in the same manner. She stated that she may have hit her head during this second game, but she was unsure. She fouled out early in the game, in part because she was called for three charging fouls. The athlete claimed that these came from her lack of depth perception; without perceiving where the opposing players were in relation to her affected her contact with them.

The following day the team returned from their tournament. At that point, the athlete informed her ATC of the situation and the signs and symptoms she was experiencing. The decision was made to follow the guidelines given by the 2 nd International Conference on Concussion in Sport ie, to follow a step-wise progression. ${ }^{1}$ At the time this injury occurred, these guidelines were the most current set of recommendations. While the recommendations since then are similar, there have been updated guidelines released more recently (Zurich, 2013 is the most recent set of guidelines). Likely the most applicable update is the position statement from the American Medical Society for Sports Medicine. ${ }^{2}$

The case study patient missed one game and returned to play for a game in one week. This was one day shorter than if the Prague guidelines ${ }^{1}$ had been exactly followed. The athlete was given exertional testing, including running, and her symptoms did not return. She also reported having no symptoms of concussion, such as headache, nausea, or vision issues. In addition, computerized cognitive testing was given to the athlete and all aspects were normal compared to her baseline test.

She played 38 minutes of the 40 minutes of the game on the day that she returned to play. Following the game she was unable to leave the bench for 10 minutes. She reported a headache scoring 7 on a scale of $1-10$, and all of her original symptoms had returned and were (according to her own perception) magnified compared to what they had previously been. Immediately following the game, the athlete went home and went to bed. The following day was a scheduled day off school (and practice) and the athlete spent the entire day in bed. The athlete did not report this to her ATC, her coach, or any of her teammates.

As noone was aware of her symptoms, and since she also denied any symptoms when asked by her ATC, the athlete continued to practice as usual. She later reported that her headache was a 2 on a scale of 1-10, and over the course of 2 weeks progressed to no headache at all. All of the other symptoms resolved within 1 week, even though she was participating fully in both practice and classes.
The athlete experienced no signs or symptoms of concussion after her headache resolved (3 $1 / 2$ weeks after the concussive blow). This period of no symptoms lasted for two months. Then, during a game, she experienced another blow to the head. Toward the end of the game, the athlete was chasing a loose ball and was struck by an opposing player. She completed the game and experienced a headache that was a 4 on a scale of 1-10. Again, she did not report the headache to her ATC, coach or teammates.

The season lasted for approximately 6 more weeks. During this time, the athlete repeatedly reported that she was experiencing no symptoms of concussion. However, she had a constant headache of 3 on a scale of 1-10 while at rest, and 4 on a scale of 1-10 while playing basketball. During this time she experienced a lack of short-term memory, difficulty concentrating, and a general feeling she described as being "out of it". These symptoms affected her academic performance and her grades were significantly lower compared to her normal academic aptitude.

The day that the season ended, the athlete reported to her ATC that she had been concealing her concussion symptoms and stated that she had been experiencing them over the last few months. She was referred to the team physician who saw her on a weekly basis. All physical activity was ceased and academic accommodations were made to ease her back into her studies. Another primary rule given to her by her ATC allowed her to perform only one task at a time eg, she was not allowed to listen to music while doing homework. The goal was to tax her brain as little as possible and minimize multitasking.

While it is impossible to know whether all of these limitations were fully followed by the athlete, she seemed to finally understand the gravity of her situation and expressed that she was taking the advice of her ATC and physician. In addition, her roommates and teammates validated that she was diligent in following the rules given to her at the end of the season.

The resolution of her symptoms happened over a span of 2.5 months. Each symptom's severity, including her academic performance and her headache, decreased as time went on and she gradually began to feel asymptomatic. After 2.5 months, once the symptoms were completely resolved, she was allowed to start light cardiovascular activity.

The first 2 weeks of her progression toward full return to play included only biking. The following 2 weeks she was allowed to combine biking with the elliptical machine. After those 2 weeks elapsed, she was allowed to begin a light weight lifting schedule. During this time she reported no symptoms 
of concussion. After that, she was allowed to start including ball handling techniques and jogging. She was cleared for full participation in basketball by the physician and ATC in mid-summer, 7 months after the original concussive blow.

The following season, the athlete was a senior on her basketball team, she had been cleared to play for five months and was experiencing no issues from her previous blows to the head. During a game, she received another blow to the head and had an immediate headache of 5 on a scale of 1-10 that she reported to her ATC, and was removed from the game. She also had a visible bump on her head. That evening she rested and took no medication. She was observed by the ATC and physician the following day. Within 24 hours her headache was a 2 on a scale of $1-10$ and within 48 hours it had reduced to a 1 on a scale of $1-10$. On day 3 , she had no headache, and it did not return with exertional testing. She was held from basketball for one additional day. She returned to play on day 5 , and reported zero symptoms of concussion.

While concussions in athletes and post-concussive syndrome are not uncommon, it is important to note several unique aspects to this story. First, the student was an athletic training student and was very cognitively aware of the risks of continuing to play while symptomatic. In addition, the patient was asymptomatic even during exertional testing and had normal computerized neurocognitive testing, and still had her symptoms return the day that she went back to play. This is a demonstration that a lack of symptoms and the presence of normal test scores does not necessarily mean that the athlete is no longer at risk when returning to play. This shows that an area of future research may be to attempt to determine at how much risk an athlete may still be at when returning to play following a concussion, even if they are symptom free and have normal cognitive testing. Also, research needs to address how best to reach athletes to help them understand the consequences of continuing to play after a concussion.

\section{Disclosure}

The author reports no conflicts of interest in this work.

\section{References}

1. McCrory P, Johnston K, Meeuwisse W, et al. Summary and Agreement Statement of the 2nd International Conference on Concussion in Sport, Prague 2004. Cl J Sport Med. 2005;15(2):48-55.

2. Harmon KG, Drezner JA, Gammons M, et al. American Medical Society for Sports Medicine position statement: concussion in sport. Br J Sports Med. 2013;47:15-26.
Open Access Journal of Sports Medicine

\section{Publish your work in this journal}

Open Access Journal of Sports Medicine is an international, peer-reviewed, open access journal publishing original research, reports, reviews and commentaries on all areas of sports medicine. The manuscript management system is completely online and includes a very quick and fair peer-review system.

\section{Dovepress}

Visit http://www.dovepress.com/testimonials.php to read real quotes from published authors. 